\title{
BIOLOGICAL MARKERS OF EARLY HEALTH EFFECTS IN THE ASSESSMENT OF THE RISK OF CANCER IN PEOPLE EXPOSED TO ENVIRONMENTAL CARCINOGENS
}

\author{
JANUSZ A. INDULSKI, WALDEMAR LUTZ and BOŻENNA KRAJEWSKA
}

The Nofer Institute of Occupational Medicine, Lodz, Poland

Key words: Biomarkers, Oncogene proteins, Carcinoembryonic antigen, Tissue polypeptide antigen, Cancer promotion, Cancer risk

\begin{abstract}
Biomarkers of early health effects represent the intermediate stages of the carcinogenesis process, between the initiation and conversion stage and the clinically overt neoplastic disease. The cellular processes indicated by those markers correspond, therefore, to the promotion process. Detection of those cellular processes is extremely important, as the promotion process lasts for many years and bears some signs of being reversible.

The promotion process, consisting of a range of consecutive cellular changes involves, among others, activation of protooncogens and their transformation into oncogens, and inactivation of the suppressor genes. Therefore, the possibility of observing the trends of those changes by monitoring protein products of the oncogens and suppressor genes in the easily available material (blood, urine) is very useful.

Inhibition of intercellular communication seems to play an extremely important role in the complex mechanism of transformation of a normal cell into a neoplastic one. During the carcinogenic process promotion stage, the inhibition is associated with the proteins which form the intercellular junctions and participate in cellular adhesion. That group of proteins includes carcinoembrional antigen (CEA) and tissue polypeptide antigen (TPA), the tumour antigens which have been known for years. The possible relationship between increased TPA and CEA concentrations is supported not only by the data from the oncology but also by the data from the studies on populations exposed to agents known to increase the risk of neoplastic disease.
\end{abstract}

The continuing chemicalization of human life associated with the development of civilization is responsible for a steady increase in health risks due to chemical pollution of the environment. Large quantities of industrial and household chemical wastes are deposited (often in an uncontrolled manner) in the vicinity of human habitation places. Toxic chemicals permeating the soil, water, or air pose a real threat to the people living in the polluted areas. In the majority of cases, the effects of exposure to environmental pollutants take the form of prolonged exposure to

Address reprint requests to W. Lutz, Department of Laboratory Diagnostics, The Nofer Institute of Occupational Medicine, P.O. Box 199, 90-950 Lodz, Poland. 
such concentrations of the pollutants which do not result in acute forms of diseases. The majority of these effects, however, lead to some biological changes in the organisms of the exposed people, and often contribute to increased incidence of chronic diseases. As no overt clinical manifestations are evident, the only way to detect minute pathological changes resulting from prolonged exposure to environmental chemicals is by detecting them on the cellular level, or in the cellular metabolism products present in the biological fluids available for testing.

The idea of biomarkers $(11,12,13,18,32)$ has become very useful in detecting the adverse effects of environmental pollution on the human organism and taking suitable preventive measures. The concept of a biomarker is associated with laboratory test of physiological fluids or cells from a person exposed to toxic chemicals: the result of the test, expressed in biochemical or cellular terms, points either to the presence or content of the toxic chemical agent, or to adverse health effects caused by the chemical agent in the human organism. The concept of a biomarker also covers an estimate of the individual susceptibility to harmful agents (12). By integrating the concepts of exposure, health effect, and individual sensitivity, enhanced analysis of the complex problem of health risk in a person exposed to environmental toxic factors has become possible. The measurements performed directly on the material taken from exposed people makes it possible to eliminate speculation from the estimations of the associated health risks. This has been made possible because the effects of toxic chemicals are not related to their concentrations in the polluted environment but to the quantities of the chemicals which have permeated the relevant tissues and organs, causing specified toxic effects.

The concept of biomarkers also made it possible to eliminate errors resulting from separately assessing the effects of occupational and communal environment pollution in a studied person. The risk to which one single person is exposed may be attributable both to the toxic pollutants present in the occupational and communal environment, as well as to the lifestyle factors, such as tobacco smoking, alcohol drinking and dietetic habits. The concept of biomarkers tends to highlight the assessment of health condition, or possible risks to health condition, rather than the assessment of the conditions of external chemical pollution (22).

At present it seems that the assessment of chemical exposure of the individual people living in a specified environment is more essential than the assessment of the chemical contamination present in that environment. The assessment can be performed either by estimating the quantity of the absorbed toxic agent with the aid of the so-called exposure biomarkers, or by assessing biochemical changes occurring in the cells of the exposed organism with the aid of the so-called health effect biomarkers.

In evaluating the adverse effects of chemically polluted environment on the human organism, most research concentrates on finding biomarkers of the carcinogenic process. The research refers both to the search for the exposure and the health effect biomarkers. In the latter case, particular attention is paid to the biomarkers of early stages of carcinogenesis. It is intended to find such biomarkers which would make it possible to detect those stages of the carcinogenesis which occur many years in advance of clinically overt cancer forms (16).

The principal stages of the carcinogenic process have already been studied in some detail, and it is known that the process involves many stages, including both cellular genetic as well as epigenetic changes $(5,33)$. The following stages can be 
distinguished in the carcinogenic process: initiaton, promotion, conversion and progression. During the first (initiation) stage, DNA is damaged as a result of exposing cells to carcinogenic agents. This change is hereditary and it is transferred to descendant cells. In the next (promotion) stage, numerous agents are involved, which do not necessarily lead to further direct changes in the genetic material of the cell, but by acting rather as gene activators and changing the phenotype of the initiated cells, cause selective and clonal cell expansion. The initiation process itself seldom leads to the formation of cancer cells when not followed by the stage of promotion. On the other hand, in order that the promotion stage could occur in the process of carcinogenesis, it must be preceded by the initiation process. The promoting agents can be described as those which display no, or very little, carcinogenic activity when they occur alone. When they are, however, combined with agents causing genetic changes in the cells (initiating agents), they remarkably enhance their mutagenic properties. During the stage of the carcinogenesis conversion process, the benign forms of cancer are transformed into malignant ones. Now it seems that this stage requires some phenomena to occur which cause changes in the DNA. Thus, both the initiation and the third (one before the last) stage of the carcinogenesis process require participation of chemical (or physical) agents which produce changes in DNA structure. Progression, the final stage of the carcinogenesis process, leads to the development of the clinically detectable form of cancer.

Each of the above stages of the carcinogenesis process can be monitored with the aid of suitable biomarkers. The initiation stage, although short-lasting, can be relatively easily monitored by employing currently available biochemical techniques (e.g. carcinogen adducts with DNA or proteins) or cytogenetic (chromosome aberrations, sister chromatid exchange, presence of micronuclei). For example, the formation of the carcinogen/DNA adducts is detectable with the sensitivity of 1 adduct per $10^{6}$ to $10^{10}$ DNA nucleotides (19). The new possibilities in detecting DNA structure changes attributable to the carcinogenesis initiation process have been opened up by the PCR (Polymerase Chain Reaction) techniques.

The information supplied by the biomarkers in evaluating the process of initiation, unfortunately, plays a limited role in cancer prevention. Although it makes it possible to demonstrate that carcinogens genotoxically affect the cells of the exposed people in the chemically polluted environment but, because the intitiation process is very short-lasting and practically irreversible, detection of the initiation process does not offer any opportunity for effective intervention (2).

The bomarkers of early health effects are essential in the prevention of the neoplastic disease induced by environmental carcinogenic agents. They provide information which is supplementary to that obtained by using the exposure biomarkers. From the data obtained by assessment of those biomarkers it can be concluded whether the exposure to environmental carcinogenic factors has triggered cellular mechanisms capable of causing neoplastic transformation. The biomarkers of early health effects represent the intermediate stages of the carcinogenesis process, between the initiation and the conversion, and the clinically overt stages. Thus, the cellular processes capable of being indicated by the biomarkers of early health effects correspond to the promotion stage. Detecting those processes is extremely important, as the promotion process lasts many years and seems to be reversible. Therefore, some preventive steps can be taken in order to prevent development of cancer (25). The biomarkers of early health effects, from this point on, referred to 
as promotion biomarkers, can be used not only to detect the early stages of the carcinogenesis process, but also to determine the efficiency of preventive steps taken (25).

As stated earlier, the promotion process, involving a number of consecutive cellular changes, does not require participation of genotoxic substances. The cellular changes, which involve activation of proto-oncogenes and their transformation into oncogenes, as well as deactivation of the suppressor genes, seem to play a dominant role in that stage. Therefore, the possibility of observing the trend of those changes through assessment of protein products of the oncogenes and suppressor genes in the easily obtainable biological material (blood serum, urine) has proved to be extremely useful (6). Currently, a number of studies have been published which attempt to correlate exposure to chemical carcinogens with changes of concentration of some oncogenic proteins in blood serum (e.g. under conditions of exposure to polycyclic aromatic hydrocarbons, polychlorinated biphenyls, asbestos, or silica) $(7,8,9)$.

The changes which lead to proto-oncogene activation and suppressor gene deactivation are not the only changes which lead to the neoplastic transformation. It seems, however, that the former correspond to the earliest stage of the promotion $(6,30)$.

Inhibition of intercellular communication by inhibiting specific intercellular junctions seems to be extremely important in the complex mechanism of the transformation of a normal cell into a neoplastic one (34). Studies on forbol esters have indicated that their ability to promote the carcinogenesis (cell canceration) is revealed by interaction with proteins responsible for the formation of intercellular junctions and cell adhesion (31). It seems interesting to note here that the carcinoembryonic antigen, a neoplastic marker known in the oncology for many years, acts as a protein responsible for intercellular adhesion $(3,23)$. The carcinoembryonic antigen (CEA) belongs to the immunoglobulin super-family which includes also e.g. the well-known adhesive protein of nervous cells. It is thought that the changes in the number of the sialic acid included in the saccharic component of the glycoproteins (to which CEA and neuronal adhesive protein belong) are correlated with the loss of the adhesive properties of those proteins (28). When evaluating the role of CEA as 'a biomarker of the promotion stage within the neoplastic process, attention should be paid to the fact that the genes for coding that protein are located in chromosome 19 , in the vicinity of the genes which code the beta growth transforming agent, or the protein kinase $C(15,35)$. The possible relationship between elevated CEA concentration in the serum and the carcinogenic process is supported not only by observations in the oncology clinics, but also by the data from studies on populations which do not display clinically overt signs of cancer process. In the latter case, elevated CEA concentrations in blood serum are found in people characterized by the occurrence of the agents which are known to increase the risk of neoplastic disease, such as age, tobacco smoking, alcohol drinking, occupational exposure to pollutants (14).

Studies published in 1986 by Pluygers et al. (26), which involved a large (2000) population of people said to be clinically healthy, have supported those suggestions. The authors have demonstrated that during a 5-year observation, the incidence of cancer in the people in whom elevated values of CEA concentration in blood serum were found during the screening tests was ten times higher than among the people with normal CEA values. 
A number of studies have confirmed that staying in an environment containing toxic chemical substances (not necessarily considered to be carcinogenic) contributes to increasing the frequency of occurrence of elevated CEA concentrations in the blood serum of the exposed people. This refers both to chemical pollutants present in the communal and in the occupational environments. Thus, Schlipköter et al. (29) observed higher values of CEA concentrations in non-smoker males residing close to industrial plants as compared with those non-smoker males who resided at some distance from the industrial region. Pluygers et al. (24) presented data on the behaviour of CEA concentrations (simultaneously, TPA concentrations were also determined) in people residing in close vicinity to refuse dumps. According to those workers, $10.3 \%$ of the tested population had elevated values of CEA concentration.

Page et al. (4) were one of the first authors who attempted using the assessments of CEA in blood serum to assess the risk of occupational cancer. They reported that in as much as $48 \%$ of the studied population working under conditions of occupational exposure to vinyl chloride, increased values of CEA concentration had been detected. During the study, overt clinical symptoms of neoplastic disease were not detected in any of the studied people. Those observations were then confirmed by Anderson et al. (1), who performed a similar study on a group of 1115 factory workers exposed to vinyl chloride in a vinyl chloride polymerization plant. Elevated values of CEA concentration were also found to occur in people occupationally exposed to asbestos dust (Jarvisalo et al.) (17). During the XXII International Congress on occupational medicine in the chemical industry held in 1987 in Sydney, Australia, Pluygers et al. (27) presented interesting reports on the application of neoplastic marker assessments, including CEA, to determine the risk of neoplastic disease in employees (subdivided into non-smokers and smokers) of three chemical plants (the type of the chemical exposure was not specified). Evidently the highest percentage of people with CEA concentration above the cut-off $(53.3 \%)$ was detected in the group of exposed smokers. Therefore, it can be concluded that tobacco smoking under conditions of occupational exposure to potentially carcinogenic chemicals increases the risk of incidence of neoplastic disease by many times.

In 1991 Pluygers et al. (25) presented data suggesting that the assessment of CEA concentration in blood serum, in combination with several other neoplastic markers (TPA, ferritin, hyalouronic acid) may be used for evaluating the risk of neoplastic disease in people occupationally exposed to asbestos dusts. The authors report that assessment of CEA concentration (and of other markers quoted above) can be helpful in evaluating the effectiveness of preventive procedures aimed at reducing the risk of incidence of asbestos-induced cancer.

The observations made heretofore indicate, however, that the use of assessment of CEA concentration in blood serum as an indicator of the risk of neoplastic disease cannot serve as a universal test for various exposures to chemical carcinogens and for various cancer types. It is thought that the assessment of CEA concentration should be accompanied by the assessment of another neoplastic marker, tissue polypeptide antigen (TPA), known for some years already in clinical oncology (10). TPA a protein of the cellular cytoskeleton, is recognized by antibodies to cytokeratins $(8,18,19)$ and is a constituent of protein intercellular junctions. Functionally, TPA is related to the family of the adhesive proteins known as cadherins, participating in cell-cell intercellular interactions. According to Pluygers et al. (25), assessment of blood serum TPA concentration as a marker of neoplastic 
disease risk is particularly useful under the conditions of exposure to those carcinogenic chemicals which display their genotoxic and mutagenic properties by forming highly active free radicals. A study by Lutz and Krajewska (20) has revealed that under conditions of exposure to carcinogenic aromatic amines, assessments of TPA concentration in blood serum performed to evaluate the risk of bladder cancer is more useful than that of CEA. Somewhat earlier Kumar et al. (quoted in 21) demonstrated that TPA can be used as a biomarker of early bladder epithelium cell changes, which can, but do not necessarily lead to neoplastic transformation.

The two discussed neoplastic biomarkers, CEA and TPA, are not the only markers which can be used for early detection of neoplastic disease risk. Nevertheless, at the current state of our knowledge on neoplastic markers, it can be said that CEA and TPA are universal biomarkers which complement each other and should be assessed simultaneously. Assessment of TPA and CEA concentration in blood serum can be supplemented by assessment of those neoplastic markers which are specific to a given exposure to chemical carcinogens or to the type of neoplastic disease they can induce. For example, under conditions of exposure to asbestos dusts, assessment of ferritin and hyalouronic acid is recommended in addition to assessing CEA and TPA concentration.

To sum up, it can be stated that assessment of some neoplastic markers (oncogenic proteins, TPA or CEA) in easily accessible biological material (blood serum) opens up new diagnostic possibilities for early detection of the risk of neoplastic disease under conditions of environmental and occupational exposure to carcinogenic chemicals.

\section{$\mathbb{R E F E R E N C E S ~}$}

1. Anderson HA, Lorimer W. Snyder J, Selikoff IJ. CEA levels in workers exposed to vinyl chloride monomer. In: The Abstract Book of the Medichem 4th International Conference. September 7-10, Haifa, 47, 1976.

2. Autrup $\mathbf{H}$. Human exposure to genotoxic carcinogens: methods and their limitations. J Cancer Res Clin Oncol 117: 6-12, 1991.

3. Benchimol S, Fuks A, Jothy S, Beauchemin N, Shirota K, Stanners CP. Carcinoembryonic antigen, a human tumor marker, functions as an intercellular adhesion molecule. Cell: 57, 327-334, 1989.

4. Bernard A, Lauwerys R. Determination of tumor markers in biological fluids. In: Indicators for assessing exposure and biological effects of genotoxic chemicals. (Ed.) A. Aitio, G. Becking, A. Berlin, A. Bernard, V. Foa, D. Kello E. Krug, A. Leonard, G. Nordberg, Office for Official Publications of the European Communities. Brussels-Luxemburg, 153-169, 1988.

5. Bishop M. The molecular genetics of cancer. Leukemia, 2, 199-208, 1988.

6. Brandt-Rauf PW. New markers for monitoring occupational cancer: the example of oncogene proteins: J Occup Med 30: 399-404, 1988.

7. Brandt-Rauf PW, Niman HL. Serum screening for oncogene proteins in workers exposed to PCBs: Brit J Ind Med 45: 689-693, 1988.

8. Brandt-Rauf PW, Smith S, Hemminki K, Koskinen H, Vainio H, Niman HL, Ford J. Serum oncoproteins and growth factors in asbestosis and silicosis patients. Int J Cancer 50: 881-881, 1992.

9. Brandt-Rauf PW, Smith S, Perera FP, Niman HL, Johannson W, Hemminki K, Sautells RH. Serum oncogene proteins in foundry workers. J. Soc Occup Med 40: 11-14, 1990.

10. Fischer L. TPA: Tracing cancer in serum and tissue. Int Clin Prod 7/8: 20-24, 1985 .

11. Fowle JR, Collins E. Health Biomarkers Program. Research Strategy Document. Office of Research and Development. Washington DC. 1991. 
12. Gunn PM, Devra L, Perera F. Biological markers in environmental epidemiology: Constrains and opportunities. In: Methods for Assessing Exposure of Human and Non-human Biota. John Wiley and Sons, Ltd. Chichester: $152-174,1991$.

13. Hanke J, Indulski J, Lutz W. Biomarkers - A new way of evaluating the effects of environment on the human organism. Med Pr 43: 63-71, 1991 (in Polish).

14. Herbeth B, Bagrel A. A study of factors influencing plasma CEA levels in an unselected population, Oncodevelop Biol Med 1: 191-198, 1980.

15. Hosier JC. Genes for tumor markers are clustered with cellular proto-oncogenes on human chromosomes. Cancer Lett 36: 235-245, 1987.

16. Indulski J, Lutz W. Biological monitoring of risk of bladder cancer in persons occupationally exposed to aromatic amines. Pol J Occup Med Environ Health 5: 143-151, 1992.

17. Jarvisallo JO, Stemman UH. Monitoring human exposure to carcinogenic and mutagenic agents. IRAC Scientific Publications 59: 403-409, 1984.

18. Join Report: Advantages and limitations of biological markers. In: Methods for Assessing Exposure of Human and Nonhuman Biota. John Willey and Sons Ltd. Chichester 10-15, 1991.

19. Lutz W, Barański B. The role of testing DNA and proteins adducts in cancer risk monitoring. Med $\mathrm{Pr}$ 42: 67-75, 1991 (in Polish).

20. Lutz W, Krajewska B. The activity of the tissue polypeptide antigen (TPA) and carcinoembryonic antigen (CEA) in the serum of workers exposed to aromatic amines. Med Pr 43: 297-301, 1992 (in Polish).

21. Lutz W. Krajewska B. Tumor marker and their significance in occupational cancer prevention. Pol Tyg Lek 45: 643-646, 1990 (in Polish).

22. Perera FP, The potential usefulness of biological markers risk assessment. Environ Health Perspect 76: $141,1987$.

23. Pluygers EP, Baldewyns PE, Beauduin M. Carcinoembryonic antigen as a marker of carcinogenesis. J Cancer Res Clin Oncol 116: 94, 1990.

24. Pluygers EP, Baldewyns PE, Gourdin P, Vandeweyer R, Minette P, Baloux C, Beauduin M. Evaluation of the cancer risk associated with activities of the chemical industry in production utilization and environmental pollution. In: Occupational. Health in the Chemical Industry. Ed: Medichem and WHO Copenhagen 220-228, 1992.

25. Pluygers EP, Baldewyns PE, Minette P, Beauduin M, Gourdin P, Robint P. Biomarker assessments in asbestos exposed workers as indicators for the selective prevention of mesothelioma or bronchogenic carcinoma: rationale and practical implementations (Parts I and II) Eur J Cancer Prev 1: 57-68, 1991 and 1: $129-138,1992$.

26. Pluygers EP, Beauduin M, Baldewyns PE. Tumor markers for cancer detection. 1 and II Cancer Detec Prev 9: 495-504 and 505-509, 1986.

27. Pluygers EP, Gourdin P. Baldewyns PE, Beauduin M. Evaluating carcinogenic risk among workers in the chemical industry by using tumor marker assessments in serum. In: Occupational Health in the Chemical Industry. Ed. Medichem and WHO Copenhagen 136-143, 1988.

28. Rutishauser U, Acheson A, Hall AK, Mann DM, Sunshine J. The neural cell interactions. Science 240: $53-57,1988$.

29. Schilpkoter HW, Baginski B, Kramer U. The carcinoembryonic antigen (CEA) in urban populations: epidemiological studies. Zbl Bakt Hyg 166: 136-143, 1978.

30. Travis CC, Belefant H. Promotion as a factor in carcinogenesis. Tox Letters 60: 1-9, 1992.

31. Trosko JE, Chang C, Medcalf A: Mechanisms of tumor promotion. Potential role of intercellular communications. Cancer Invest 1: 511-526, 1983.

32. US National Research Council: Biological markers in environmental health research. Environ Health Perspect 74: 1-191, 1987.

33. Weinstein BI. The origin of human cancer: Molecular mechanisms of carcinogenesis and thier implications for cancer prevention and treatment. Twenty-seventh GAA Clowes Memorial Award Lecture. Cancer Res 48: 4135-4143, 1988. 
34. Yamasaki H. Gap junctional intercellular communication and carcinogenesis. Carcinogenesis 11: $1051-1058,1990$.

35. Zimmermann W. Chromosomal localization of the carcinoembryonic gene family and differential expression in various tumors. Cancer Res 48: 2550-2554, 1988.

Received for publication: February 15, 1993

Accepted for publication: April 7, 1993

\title{
DIARY OF CONFERENCES AND SEMINARS
}

\author{
June 4-6 1993, Prague, Czech \\ 6th International Symposium of the Physical Medicine Research Foundation \\ Info: North American Secretariat, Physical Medicine Research Foundation, \\ Suite 510-207 West Hastings Street, Vancouver, BC., V68 1H7 \\ Tel. (604) 684 4148, Fax (604) 6846247 \\ European Secretariat, Czech Medical Society, Sokolská 31, 12026 Praha 2, Czech \\ Tel. (42 2) 2968 89, Fax (42 2) 2352412 or 294610 \\ Main topics: \\ * Industrial myoskeletal discorders, \\ * designing prevention and cost effictive rehabilitation programmes.
}

\section{June 6-11 1993, Elsionore, Denmark}

4th Meeting of the International Neurotoxicology Association

Info: Dr Ole Ladegoged, Dept. of Pathology, Inst of Toxicology,

National Food Agency, 19 M $\phi$ rkh $\phi$ j Bygade, DK-2860 S $\phi$ borg, Denmark

Tel. (45 39) 696600 , Fax (45 39) 660100

Main topics:

* Toxicants and neurodegenerative diseases,

* Toxicants and cognitive functions,

* Experimental methods in screening for neurotoxicity,

* New methods in neorotoxicity,

* Structure activity studies,

* Transgenic animals,

* The role of hippocampus and the limbic system. 